\title{
INVESTIGACIONES
}

\section{Experiencias estudiantiles en el primer año universitario. Una aproximación desde la sociología de la educación francesa*}

\author{
Freshman experiences at the university. \\ An approach from the French sociology of education \\ Rodolfo Martinic ${ }^{a, b}$, Sergio Urzúa-Martínez ${ }^{c}$ \\ ${ }^{a}$ Doctorando en Sociología en l'École des Hautes Études en Sciences Sociales, Francia. \\ rodolfomartinic@gmail.com \\ ${ }^{b}$ ANID - Programa Iniciativa Científica Milenio - Núcleo Milenio Autoridad y Asimetrías de Poder. \\ ${ }^{c}$ Doctorando en Ciencias Sociales Universidad de Buenos Aires, Argentina. \\ Universidad de Santiago de Chile-IESED. \\ sergio.urzua@usach.cl
}

\section{RESUMEN}

A la luz de los estudios sobre la experiencia estudiantil en la universidad de masas de la sociología de la educación francesa, buscamos comprender cómo los estudiantes de primer año universitario experimentan su proceso de transición a la universidad. A través de una investigación cualitativa basada en el análisis de ocho grupos focales en que participaron 42 estudiantes de la Universidad de Santiago de Chile, evidenciamos que la experiencia en el primer año constituye un proceso de socialización complejo marcado por una serie de discontinuidades respecto a la etapa escolar: una fuerte declinación de las evidencias académicas previas, un déficit de preparación académica atribuido a la educación escolar y una readecuación de las rutinas y hábitos para gestionar el tiempo y el estudio universitario. En las conclusiones se destacan los aportes del estudio y se propone una agenda de investigación para futuros estudios en el área.

Palabras claves: Educación Superior, Primer Año Universitario, Transición a la Universidad, Sociología de la Educación.

\section{ABSTRACT}

Based on research in the French sociology of education on the experience of students in the mass university, the article considers the way in which first-year students deal with their transition to a chilean public university. Through data reported from eight focus groups with 42 students from the University of Santiago de Chile, it showed that first-year experience constitutes a complex socialization process scarred by a series of discontinuities regarding the school: strong decline in previous academic evidence, deficit in academic preparation attributed to school education, and a readjustment of routines and habits to manage time and study. The conclusions highlight the contributions of the study and propose a research agenda for future studies in the area.

Key words: Higher education, First-year student, Transition to college, Sociology of education.

\footnotetext{
* Esta investigación fue realizada gracias al Ministerio de Educación del Gobierno de Chile a través de su programa MECESUP.
} 
Estudios Pedagógicos XLVII N 2: 161-178, 2021

EXPERIENCIAS ESTUDIANTILES EN EL PRIMER AÑO UNIVERSITARIO. UNA APROXIMACIÓN DESDE LA

SOCIOLOGÍA DE LA EDUCACIÓN FRANCESA

\section{INTRODUCCIÓN}

El proceso de masificación de la educación terciaria en Chile, al igual que en otros países de América Latina, se ha caracterizado por un aumento sostenido en la matrícula, la diversificación de programas de estudios y la mayor oferta educativa privada (Espinoza, 2017). No obstante, este proceso logra diferenciarse del experimentado por otros países de la región en la impronta neoliberal que adquirió el sistema de educación superior chileno derivada de las reformas estructurales implementadas desde 1980 (Bellei et al., 2014). Consecuencia de estas reformas se estableció un marco institucional con bajas barreras de entrada para proveedores independientes, permitiendo que el mercado de educación superior operara sin mayores restricciones y con escaso mecanismos de control de calidad y rendición de cuentas (Brunner, 2008).

De esta forma, en Chile, la diversificación de la oferta educativa permitió el crecimiento desproporcionado de la matrícula terciaria, que sumado a las "políticas de ampliación de oportunidades" (Chiroleu, 2013) implementadas durante las últimas dos décadas, cambiaron el perfil del estudiantado y aportaron mayor heterogeneidad social y diversidad al sistema. En este marco, los estudios a nivel nacional se han ocupado preferentemente de conocer cómo ha sido la transición a la educación superior de aquellos jóvenes que provienen de contextos sociales desventajados, asumiendo que la formación escolar es altamente desigual a la hora de enfrentar las demandas en la universidad. Esto, como resultado de la fuerte segregación que afecta al sistema escolar chileno, donde la calidad de los establecimientos educacionales al que los jóvenes acceden se ve limitado por el nivel socioeconómico y el capital cultural de sus familias (Valenzuela et al., 2014).

En este trabajo buscamos interpretar las experiencias estudiantiles en la transición a la educación superior a partir del caso de una universidad estatal, tomando distancia de los estudios que describen la conducta de los jóvenes exclusivamente a partir de su posición en la sociedad. Sin desconocer los aportes de la teoría de la reproducción social, específicamente de los estudios que utilizan la noción de habitus, buscamos realzar una comprensión de la transición de la escuela a la universidad a partir de las herramientas de la sociología de la educación francesa posterior a los trabajos de Pierre Bourdie (Fave-Bonnet \& Clerc, 2001; Guzmán, 2002). A través de ella, se buscó generar una lectura de la transición de los estudiantes a la universidad como un proceso complejo, no reductible a las lógicas de "una" institución y donde varios procesos de socialización participan y se articulan.

Así, reconociendo que la comprensión de las maneras en que los estudiantes de diferentes grupos sociales acceden y persisten en la educación superior ha favorecido la implementación de programas y políticas correctivas (Canales y De los Ríos, 2009; Leyton et al., 2012; Gallardo et al., 2014; Micin et al., 2015; Soto-Hernández, 2016; Martinic, 2019), consideramos que este único eje analítico no permite observar con la atención requerida el tránsito mismo de los estudiantes, ni las discontinuidades que este proceso aloja. Desde ahí, nuestro trabajo considera que la transición es un proceso liminal en el que los estudiantes se encuentran (al menos) entre dos instituciones -escuela y universidad-, no siendo posible delimitar sus comportamientos e identidades a las lógicas de ninguna de éstas.

Se trata, entonces, de un esfuerzo por indagar en las discontinuidades experimentadas por los estudiantes en tanto dificultades, oportunidades, ambivalencias e incapacidades que amenazan su permanencia en la educación superior. Para responder a ello, el estudio considero un enfoque cualitativo en el cual consideramos la realización de ocho grupos 
focales. En las conversaciones participaron 42 estudiantes de primer año de la Universidad de Santiago de Chile (USACH) y el análisis de la información se realizó a través de las herramientas de codificación de la grounded theory.

Además de esta introducción, el artículo se estructura en cinco apartados. En el primero, presentamos la evolución de la sociología de la educación francesa desde la noción del estudiante "heredero" hasta la emergencia de los nuevos estudiantes, con el fin de evidenciar la transformación de la universidad desde una institución de élite a una de masas. En segundo apartado exponemos la metodología y argumentamos a favor de la elección de los grupos focales como una técnica adecuada para conocer las experiencias de los estudiantes. En el tercer apartado, damos cuenta de los principales resultados del estudio a la luz de los estudios sobre transformaciones de la experiencia del estudiante en la universidad de masas; y en el cuarto, presentamos las conclusiones del estudio e incluimos algunos puntos que permitirían ampliar y profundizar el estudio de las experiencias de los estudiantes en la educación superior.

\section{MARCO TEÓRICO}

\subsection{DEL "HEREDERO" A "LOS NUEVOS ESTUDIANTES": LA SOCIOLOGÍA DE LA EDUCACIÓN} FRANCESA EN LAS ÚLTIMAS DÉCADAS

Desde la segunda mitad del siglo XX, los estudiantes universitarios han sido un objeto de estudio privilegiado en la sociología de la educación francesa. Sin embargo, las aproximaciones han evolucionado con el correr de los años. En efecto, las preguntas de Bourdieu y Passeron centradas en la reproducción social generada por un sistema de enseñanza elitista, se han trasladado a las transformaciones que experimentan los estudiantes en la universidad de masas (Jellab, 2011) la construction du projet d'apprendre et l'élaboration d'un projet professionnel (ou de projets d'avenir). El estudio del mundo estudiantil ha permitido analizar las crisis y evoluciones de la enseñanza superior, y al mismo tiempo evidenciar el desarrollo que ha tenido la sociología de la educación. El panorama que se ha dibujado al interior de la subdisciplina, siguiendo a Fave-Bonnet y Clerc (2001), permite distinguir cuatro periodos.

El primero considera las investigaciones de los años 60 y 70, las cuales estuvieron centradas principalmente en problemáticas sociopolíticas que llegarán a ser álgidamente debatidas durante mayo del '68. Por supuesto, el epítome de estos trabajos lo representa Los herederos de Pierre Bourdieu y Jean Claude Passeron (2012), en el cual se busca demostrar el rol de las instituciones de educación superior en la reproducción de las desigualdades sociales. Oponiéndose a una sociología que considera a las instituciones de manera aislada a su entorno social, los autores sostienen que -antes que el talento o el mérito individual-, es el origen social, enmascarado bajo la ideología del "don", el factor determinante del éxito de los estudiantes. Así, si los jóvenes seleccionados provienen de las clases privilegiadas, aquello es en gran medida a causa de que los criterios utilizados para seleccionar han sido modelados en sintonía con el "éthos" de la élite.

En el segundo periodo situado entre finales de los 70 y principios de los 80, la investigación en sociología si bien mantiene la preocupación por las críticas del periodo anterior, se ve influenciada por una coyuntura particular: la crisis económica del '74, el 
desempleo y una toma de consciencia por parte de la población estudiantil de que los estudios permiten el acceso a mejores salarios (Fave-Bonnet \& Clerc, 2001). La problemática que adquiere relevancia entonces se centró entonces en torno a la cuestión de la legitimidad de la institución superior y de sus funciones sociales. Aquello dio lugar a estudios que profundizaron en la relación entre la masificación de la universidad y su democratización, como también a un conjunto de perspectivas que comienzan a concebir al estudiante en tanto "actor". En esta línea se encuentran los trabajos de Boudon y Touraine; mientras que el primero entiende la desigualdad social y su reproducción como el resultado de la agregación de conductas individuales, el segundo -en sintonía con las demandas sociales de mayo del 68- el estudiante deviene un actor comprometido en un movimiento social que disputa el control social sobre las orientaciones culturales de la sociedad.

Durante la década de los ochenta tiene lugar el tercer período, en el cual incipientemente se comienza a dar cuenta de las diferentes identidades estudiantiles que se forjan en el seno de las distintas carreras o planes de estudio (Fave-Bonnet \& Clerc, 2001). Aquello ocurre en un contexto en donde el Estado busca regular las dificultades de orientación profesional generadas a partir de la creciente masificación del sistema universitario. Por ello, los temas que preocupan a los investigadores del período son principalmente la orientación y la inserción profesional. Se estudian los elementos afectivos de las decisiones de los estudiantes, sus trayectorias en sus respectivas carreras y las maneras en que se incorporan al mercado laboral.

Finalmente, la ola de estudios que se comienza a generar a partir de los 90, abordan ya de manera decisiva las transformaciones de la experiencia del estudiante en la universidad de masas, poniendo énfasis en los cambios que afectan sus estilos de vida, las relaciones que establecen con sus compañeros, profesores y la institución en general, así como las maneras de estudiar o de la forma en que desarrollan el trabajo universitario (Fave-Bonnet \& Clerc, 2001). Es este cuarto periodo que sirve de referencia a este estudio y el cual desarrollaremos a continuación con mayor detalle mostrando sus principales aportes.

\subsection{LA EXPERIENCIA UNIVERSITARIA EN LA UNIVERSIDAD DE MASAS}

La experiencia universitaria pasa, entonces, a estar en el centro de las preocupaciones en los nuevos abordajes de la sociología francesa. La conformación de esta experiencia, como señala Felouzis (2001), es el resultado de dos importantes fenómenos. El primero, propio de Francia, que deriva de la gran diferenciación institucional de la enseñanza superior y que es posible observar en la coexistencia de un conjunto de escuelas y de estructuras diversas (Renaut, 1995). El segundo, es propio de las sociedades más avanzadas y refiere a la democratización de la enseñanza, comprendida en el acceso creciente de jóvenes generaciones a la educación superior. La confluencia de estos dos fenómenos convierte a la universidad de masas en la universidad de la indecisión y de las dificultades de integración, la que se revela tanto a los ojos del investigador como de los mismos estudiantes como una institución fragmentada carente de un poder social que cohesione (Erlich, 1998).

Como dirá Dubet (1994), la universidad se ha tornado un espacio cada vez más ambivalente: se ha masificado aumentando el número de estudiantes y se ha convertido en un espacio más heterogéneo en cuanto a la diversidad de orígenes, trayectorias educativas y proyectos de los estudiantes. Por lo mismo, el estudiante ya no sería identificable tanto por su origen social, sino por las distintas modalidades de habitar la universidad. No 
sería posible, por tanto, hablar de "un" tipo de estudiantes porque existirían entre ellos "situaciones objetivamente diferenciadas" relacionadas con las condiciones de vida, la carrera que ingresan a estudiar, el grado de familiaridad con la cultura escolar (que puede llegar a ser una ventaja en los estudios) y la manera de asumir la transición según los sexos (Boyer, Coridian \& Erlich, 2001). De ahí la dificultad de hablar de un "estudiante promedio" como una figura ideal que encarna formas típicas de estudiar y de afiliarse a la universidad (Grignon \& Gruel, 1999).

Un conjunto importante de investigaciones se aboca a la comprensión de las experiencias que viven los estudiantes al ingresar a la universidad. Una "socialización silenciosa" a través de la cual se llega a ser a ser estudiante y que conlleva forzosamente la interrupción del estilo de vida que se llevaba en la educación secundaria (Lahire, 1997). Así, es posible hallar en ellas el supuesto compartido de que la identidad de estudiante no es algo dado sino el producto del trabajo del individuo sobre sí mismo.

Para Dubet (1994), cada estudiante estaría mandatado a "fabricar" su experiencia en la universidad estableciendo una relación con los estudios a partir de los principios (o lógicas de acción) que rigen en el sistema de educación superior. Estos principios que estructuran la experiencia de los individuos y definen el sentido subjetivo de los estudios, corresponderían al proyecto, la integración y la vocación. Mientras que el proyecto considera la dimensión estratégica de los estudios, en la cual el estudiante se representa la utilidad de estos y define objetivos, evalúa estrategias y sopesa sus costos; la integración alude tanto a la forma como al nivel de implicación que el estudiante sostiene con la organización a la cual pertenece. La vocación, por último, se asocia tanto al interés en los estudios como al sentido educativo y personal que cobra la carrera, expresado en un sentimiento de auto-realización intelectual ahí involucrado. A través de una combinatoria que da lugar a una geometría variable, los estudiantes construyen su experiencia en la universidad articulando de diferentes maneras estos tres principios de acción.

Inscribiéndose en la etnometodología, Coulon (2005), por su parte, entiende el ingreso a la universidad como un proceso de "afiliación", mediante el cual se adquiere un nuevo estatus social: el de estudiante. Como un rito de pasaje, quien sale de la educación secundaria debe aprender a convertirse en estudiante a través del descubrimiento, las rutinas, reglas y evidencias que configuran el medio universitario. Por ello, lo que está en juego en el ingreso a la universidad es la adquisición del "oficio" de estudiante, el cual se basa en el aprendizaje de los códigos institucionales e intelectuales fundamentales para llevar a cabo el trabajo de estudiante. Detentar el "oficio" de estudiante es llegar a sentirse un "pez en el agua": moverse con naturalidad y desenvoltura en el contexto universitario, habiendo internalizado, al punto de constituir en evidencia, las instrucciones para llevar a cabo con éxito el trabajo académico. Así también, el fracaso académico y el abandono de los estudios son indicativos de la dificultad que enfrentan ciertos estudiantes para detectar, descifrar y luego incorporar los códigos universitarios. En este sentido, Coulon ha destacado los factores que contribuyen a frustrar la afiliación de los estudiantes a la universidad: se trata del "fracaso del sistema de información y orientación", la pedagogía universitaria "casi inexistente" o el desarrollo en nuevos estudiantes, de una relación utilitaria con el conocimiento, que contrasta con las expectativas de las instituciones académicas.

Grignon y Gruel (1999), por otro lado, tienen el mérito de considerar la dimensión de los costos asociados al ingreso a la educación superior en la experiencia. Esto, dado que convertirse en un estudiante es un aplazamiento del ingreso al mercado laboral y, por tanto, 
también retrasa la independencia financiera. Aquello hace que la prosecución de estudios no sea una mera decisión individual, sino que involucra en gran medida a la familia. De hecho, sobre todo al comienzo de los estudios, la ayuda familiar juega un papel importante que permite a los estudiantes sostener las condiciones de vida. Sin embargo, la situación de dependencia cambia significativamente con el paso de los años. El avance en la edad y el progreso en los estudios se acompañan de una "verdadera metamorfosis estatutaria", que implica una independencia no sólo económica, sino que también emocional: al recibir cada vez menos ayudas públicas o parentales, los estudiantes comienzan a obtener sus propias fuentes de ingreso, al tiempo que se independizan de los padres. Los estudios universitarios, así, constituyen también una forma de emancipación del entorno familiar, de transitar hacia la edad adulta a través de un calendario y de estrategias que varían según el tipo de estudios y los recursos con los que, estudiantes de diversos orígenes, disponen.

De manera similar aunque desde el interaccionismo simbólico, Felouzis (2001) describe los cambios de la experiencia universitaria a partir de la "condición de estudiante". Esta conlleva estar confrontado a una institución débil en la cual los modos de regulación han desaparecido y que da lugar a una suerte de "individualismo negativo" impuesto por la ausencia de un verdadero cuadro institucional: los estudiantes se encuentran en un mundo en donde ningún horizonte ni objetivo les son propiamente ofrecidos. Confrontados a un mundo de "exigencias sin coerciones", los estudiantes perciben que las reglas del juego escolar cambiaron, sin que ninguna regla que sea explícitamente formulada. Por ello, el primer año universitario consiste en el "develamiento de un enigma" que los implica personalmente. Ya sea por la indiferencia de los profesores, la incertidumbre ligada a los exámenes o el sentido de la carrera que se estudia, los estudiantes tienen a menudo el sentimiento de estar en juego "personalmente". Así, la condición de estudiante consiste en una paradoja, en la cual la indeterminación de fines y medios es acompañada de la "obligación moral" de aprobar los cursos y lograr el diploma. El descubrimiento de su condición es hacer frente a la necesidad de crear en sí mismos y por sí mismo los objetivos de su acción y los medios para alcanzarlos. La identidad "estudiante" no es solo una condición sino también una acción, como construirse "motivaciones" o "imponerse" obligaciones en el marco de los estudios.

Desde otra perspectiva Boyer et al. (2001), sostienen que el ingreso a la universidad no puede ser concebido únicamente a partir de las modalidades de afiliación intelectual y social, pues es también una transformación de los modos de vida que configuran la identidad de estudiante. Así, la transición es un proceso que conlleva un conjunto de rupturas: a) se desestructuran los marcos de vida y de los estudios, pues la transición supone el contacto con un nuevo espacio urbano en el cual hay que aprender a orientarse (especialmente en el caso de los estudiantes de otras ciudades); b) se reconstruyen los puntos de referencia temporales, pues el ingreso es también un momento de desregulación del marco temporal, caracterizado por la irregularidad y discontinuidad de los horarios universitarios; y c) se experimentan nuevos métodos de enseñanza y se deben enfrentar nuevas situaciones pedagógicas, lo que constituye un gran desafío de adaptación para los nuevos estudiantes. Por último, los jóvenes también deben enfrentar la incertidumbre del trabajo universitario, comparativamente mayor al realizado en la educación secundaria.

En relación a este último punto, el trabajo universitario en tanto formas de estudio que los jóvenes deben adquirir y desarrollar, es uno de los elementos de mayor relevancia en los trabajos sobre transición a la universidad. Para Lahire (1997), las "formas de 
estudiar" consisten en maneras de aprender que se expresan en las prácticas informales y en el comportamiento adoptado por el estudiante para estudiar, como la adaptación al ritmo del trabajo académico, la organización de los horarios, las prácticas de lectura y las condiciones materiales del trabajo académico. En este marco, el estudiante se forma en la definición del tiempo: tiempo de clases, de tiempo de trabajo personal, un tiempo de ocio y, eventualmente, un tiempo de trabajo remunerado, para lo cual es necesaria una socialización en la organización del tiempo y las relaciones entre el tiempo de estudio y el tiempo libre; en otras palabras, en la toma de conciencia del tiempo propio.

\section{METODOLOGÍA}

Como hemos señalado, el objetivo del presente trabajo fue comprender las experiencias de los estudiantes en el marco de su transición a la universidad, analizando las dificultades de las demandas académicas desde las discontinuidades que experimentan más que desde sus respectivas posiciones sociales.

Para esto, el estudio se basó en una metodología cualitativa que contempló la realización de ocho grupos focales en los que participaron 42 estudiantes de primer año de la Universidad de Santiago de Chile ${ }^{1}$. La recolección y el análisis de la información derivada de los grupos de discusión se realizó bajo el método de la grounded theory (Strauss \& Corbin, 2002). El análisis considero dos etapas. En primer lugar, la codificación abierta implicó la lectura completa de las transcripciones de los grupos focales siguiendo la lógica del microanálisis, el cual implicó un examen minucioso de cada fragmento de conversación. Estos fueron descompuestos en categorías, unidades discretas de significados que luego fueron comparadas entre sí en busca de similitudes y diferencias. En segundo lugar, en la codificación axial se reagruparon estas categorías, vinculando las unidades en clasificaciones de mayor generalidad que permitieron una comprensión a la vez más amplia y precisa de la experiencia de los estudiantes.

Los grupos focales fueron realizados en instalaciones de la universidad al término del primer semestre del año 2016. Para introducir y enmarcar la conversación se presentó un video donde algunos estudiantes contaban sus dificultades durante el primer año académico. La pauta de preguntas consideró, además de una discusión en torno al video, preguntas sobre las expectativas previas al ingreso, los primeros días de clases y la relación con sus compañeros, profesores y funcionarios de la universidad; así como también, las principales dificultades que enfrentaron en el transcurso del semestre.

En este marco, el grupo focal es una técnica que permite acceder al conocimiento social o común de los individuos, al conjunto de presunciones sostenidas intersubjetivamente en tanto que "real", "obvio" o dado por sabido en las acciones y comunicaciones de un colectivo (Canales, 2006). Así, a través del grupo focal logramos acceder a los sentimientos, creencias y opiniones de los estudiantes sobre el primer año universitario. La utilización de esta técnica creemos que fue la acertada, ya que propició el sentido de pertenencia a un grupo, brindando la sensación de cohesión y de seguridad para hablar sobre sus experiencias. Con esto, las interacciones que tuvieron lugar en el grupo focal, posibilitaron

El grupo compuesto por 24 mujeres y 18 hombres (edad promedio, 18 años), provenían de 25 carreras (cuatro facultades de la universidad). Todos firmaron un consentimiento informado que garantizó su anonimato. 
respuestas más espontáneas y la generación de un ambiente en donde los participantes pueden discutir problemas personales de manera colectiva (Onwuegbuzie et al., 2009).

\section{RESULTADOS}

A partir de los grupos focales encontramos tres elementos que estarían a la base de la identidad que construyen los estudiantes en universidad: a) la declinación de las evidencias o certezas del colegio que experimentan los estudiantes; b) la discontinuidad en la transición universitaria que los estudiantes perciben producto, principalmente, del déficit de preparación académica (atribuido a los colegios de procedencia); y c) las exigencias académicas universitaria demandan una nueva manera de gestionar el tiempo y el estudio en la universidad.

\subsection{LA DECLINACIÓN DE LAS EVIDENCIAS ESCOLARES: CÓMO SE ENFRENTA LA CONDICIÓN DE ESTUDIANTE}

En la conversación observamos que a medida que avanzaba el semestre fueron declinando las evidencias (Dubet \& Martuccelli, 1997) que aún se conservaban de la etapa escolar. Así, lo que se solía dar por hecho comienza a tornarse una fuente importante de incertidumbre. Hablamos, concretamente, de las certezas que los jóvenes construyeron a través de su socialización escolar sobre lo que significa ser un buen estudiante, las estrategias que se deben desplegar para conseguirlo, el modo de relacionarse con los profesores y con la escuela, entre otros. El paso a la universidad remece las disposiciones construidas en la etapa escolar, obligando a los estudiantes a elaborar una nueva batería de certezas en un medio educativo que les demanda un mayor grado de autonomía.

Al ingresar a la universidad, los estudiantes dejan atrás un espacio cargado de familiaridades y en donde la organización escolar se hacía cargo de un conjunto de ámbitos sobre los cuales los jóvenes no tenían que decidir. En las conversaciones los estudiantes evocan una representación de la escuela en tanto espacio estructurado, de vínculos más cercanos y con normas claramente establecidas (dadas por padres, profesores o la misma institución) que permitían que fuese más sencillo orientarse.

El espacio protegido [del liceo] donde todo es, ya, como que ahí los profes están pendientes de todos los alumnos, te ayudan, te dan tareas... acá no po', acá uno ya está grande y tiene que hacerlo todo por uno, claro y eso igual me ha costado (Hombre, Ingeniería Civil Química).

La novedad de la etapa universitaria es que trasfiere a los estudiantes estas responsabilidades y genera un nuevo espacio de autonomía. En efecto, la socialización universitaria, a diferencia de la escolar, es una tarea que exige mayor participación de los estudiantes y una experiencia que co-producen en las interacciones, principalmente con los pares y profesores en ausencia reglas explícitas.

Yo entré a la universidad el primer día y no quería ir, no me gustaba el ambiente, no me gustaba la gente, no me gustaban los profes, nada, nada, nada. [...] yo creo que fue 
todo el conjunto, pasar del colegio a mandarte sola en la ' $u$ ', tener que tú hablar con los profes, yo creo que eso como la independencia que genera” (Mujer, Bachillerato en ciencias y humanidades).

En la conversación, los estudiantes oponen la experiencia escolar a la autonomía que descubren en la universidad, la que, a su vez, es vivida con un alto grado de ambivalencia, pues si bien la autonomía conlleva mayor libertad al dejar atrás las restricciones de la etapa escolar, dicha libertad también genera sentimientos de inseguridad y aprensión. Esta ambivalencia se relaciona con lo que Felouzis (2001) denomina "individualismo negativo" y su origen está en la débil regulación y normas de acción que tiene la universidad.

Una fuente importante de esta desestabilización emocional se relaciona con el declive en los estudiantes de la autopercepción de ser "buenos alumnos" fundada en un destacado desempeño académico escolar. En efecto, para muchos, en el primer semestre no fue posible conseguir los mismos buenos resultados en las evaluaciones. De esta manera, resulta común pasar de tener las mejores calificaciones del curso a reprobar en las asignaturas importantes y con fortuna, en algunas ocasiones, lograr una nota de aprobación.

Yo creo que todos acá tenían arriba de seis o cinco por lo menos, pero eran [...] más que nada buenas notas [...] entonces eso igual a mí como que me ha desmotivado, igual me hace pensar el caso mío por qué no continué trabajando, después estudié, me preparé mejor (Hombre, Ingeniería Eléctrica).

La imagen de sí mismos que construyeron en el colegio en tanto estudiantes, cae estrepitosamente. La frustración de pasar de ser uno/a de los mejores estudiantes del curso en el colegio a enfrentar serias dificultades para aprobar las asignaturas en la universidad, remece la autoestima forjada en la etapa escolar. Con cierto asombro, en las conversaciones abundaron referencias a que en el colegio bastaba hacer las tareas, leer los apuntes antes de las pruebas o prestar atención en clases para que les fuera bien. Las pruebas del primer semestre alertan tempranamente que, de mantenerse las mismas estrategias de estudio, ya no será posible continuar siendo en la universidad él/la mismo/a del colegio. El trabajo universitario, por ello, parece ser inconmensurable en relación al trabajo escolar. Aquello lo refleja un estudiante que luego de constatar lo anterior, relata cómo se dio cuenta de la ausencia de directrices del estudio en la universidad.

Yo una vez llegué acá, pasó como una o dos semanas y no estudié nada [... ] y uno cae en otro problema que no sabe dónde estudiar, porque ahí los profes, acá los profes ya no te dicen 'ya estudia esto, estudia esto', no, los profes directamente ya no te enseñan, sino hacen clases, entonces uno por la de uno tiene que, por las de uno tiene que aprender más cosas (Hombre, Ingeniería Civil Química).

Asimismo, esta frustración es acompañada del cuestionamiento de las propias capacidades y de la decisión de haber ingresado a la universidad. En efecto, no poder replicar el rendimiento académico del colegio en la universidad, afecta fuertemente el ánimo de los estudiantes y se convierte en una fuente de inseguridad que los lleva a dudar sobre si podrán sobrellevar hasta el final las exigencias académicas de la carrera. De hecho, en ocasiones el golpe de dejar de ser el "buen estudiante" escolar y la inseguridad que han 
Estudios Pedagógicos XLVII Nº 2: 161-178, 2021

EXPERIENCIAS ESTUDIANTILES EN EL PRIMER AÑO UNIVERSITARIO. UNA APROXIMACIÓN DESDE LA

SOCIOLOGÍA DE LA EDUCACIÓN FRANCESA

cimentado los malos resultados, suele asociarse al desencadenamiento de estados nerviosos y el "bloqueo" en las pruebas.

Es que los uno o cuatro no existían en la media, entonces me da como pena, como que me duele, yo pude haberlo hecho mejor, es que siempre hay algo que me pone nerviosa, sé hacerlo, pero como que lo veo y me bloqueo (Mujer, Química y farmacia).

La familia, en este contexto, si bien puede ser un soporte importante para los estudiantes, al mismo tiempo puede aportar cierto grado de presión que dificulta que los estudiantes sobrelleven las situaciones difíciles. En efecto, el hecho de ser primera generación en la universidad o la añoranza de que el/la hijo/a sea el "ingeniero/a de la familia", generan expectativas con las que los estudiantes -directa o indirectamente- tienen que cargar y que redundan en un sentimiento de no poder fallar. Aquello reenvía a la paradoja de la condición estudiante señalada por Felouzis (2001), en la cual la "obligación moral" de aprobar los cursos tiene como telón de fondo la indeterminación de las orientaciones normativas.

Por otra parte, el cambio de la naturaleza de la relación profesor-estudiante también juega un rol en este declive de las evidencias escolares. Los estudiantes comprueban que en la universidad la relación con los profesores no se da en los mismos términos que en la escuela, ya que mientras que en esta última los profesores se caracterizarían por su preocupación y cercanía hacia los estudiantes, en la universidad la relación sería más distante y circunscrita a los módulos en que se realiza la asignatura. En ese sentido, buena parte de la sensación de abandono que experimentan los estudiantes durante el primer semestre universitario se relaciona con la impersonalidad del trato: "los profesores no son como en el colegio, como que ellos hacen su clase y se van entonces si uno queda con dudas no tiene a quién recurrir" (Hombre, Ingeniería en Ejecución en Metalurgia). La distancia con el profesorado, según sea el caso, es experimentada de diferentes formas, desde la diferencia edad, el sentir que son una autoridad intimidante e incontestable o, al contrario, considerar que no poseen las competencias pedagógicas para enseñar y que se limitan a recitar los contenidos de un power point: "al entrar a la Universidad nos tocó un profesor [...] que no es malo, es muy viejito e igual se le entiende... no le escucho nada y pasa puro power". Todo ello, si bien como señala Coulon (2005) problematiza la afiliación de los estudiantes, obliga a los estudiantes a crear y recrear suplementos al déficit pedagógico.

\subsection{LA DISCONTINUIDAD EN LA TRANSICIÓN UNIVERSITARIA: LA ATRIBUCIÓN DE UN DÉFICIT EN LA FORMACIÓN ESCOLAR}

Pese a la percepción de "buen estudiante", los estudiantes resaltaron la escuela no les brindo una preparación acorde a las exigencias universitarias. Algo que ha sido identificado en otros estudios y que se ha interpretado desde la reproducción social como la facilidad o la dificultad de los estudiantes para ajustarse a la universidad en función del habitus dado por el origen social (Canales y De Los Ríos, 2009; Leyton et al., 2012), acá se busca complementar con otra mirada, a saber, la de la discontinuidad-sobre todo a nivel de currículo- existente entre el sistema escolar y la universidad.

Una lectura así no niega ni las desigualdades ni la generación de disposiciones individuales asociadas a una posición social. Ello porque en el país las posiciones se hacen 
más inconsistentes, añadiéndose a los tradicionales ejes estructurantes -empleo, ingresos y educación- una diversidad de otros factores como el capital social, la naturaleza de las redes sociales, el dominio de los códigos culturales dominantes, la importancia del sector donde se vive, entre otros. Los factores de posicionamiento social, entonces, se multiplican, haciendo más complejo determinar quién está "arriba" o "abajo" y abriendo la posibilidad de experimentar de manera simultánea y contradictoria movilidades "ascendentes" o "descendentes" (Araujo y Martuccelli, 2011). El resultado de ello, siguiendo a Boyer et al. (2001), es que las experiencias de los estudiantes en la universidad se dan en el marco de "situaciones objetivamente diferenciadas".

En ese contexto, por sobre la explicación disposicional asociada al origen social, la hipótesis de nuestro análisis hace del hiato entre la formación escolar y las exigencias universitarias uno de los principales elementos interpretativos del déficit de preparación que se suelen atribuir los estudiantes en el primer año. El distanciamiento que hay entre ambos mundos se hace más agudo, ciertamente, si se compara a los estudiantes provenientes de escuelas privadas y públicas y, especialmente, entre la formación humanista-científico (HC) y técnico-profesional (TP); sin embargo, con diferencia de grados y matices, los estudiantes asumen individualmente un problema que parece ante todo estructural.

En algunos casos, los estudiantes se dieron cuenta de aquello, al constatar la brecha de conocimientos que tenían en ciertas asignaturas respecto a compañeros que provenían de "mejores" colegios. Una estudiante, por ejemplo, que estudio en un colegio particular subvencionado y terminó su enseñanza media con 6,4 de promedio, ilustra a través de su experiencia dicha brecha en relación a sus compañeros que provenían de escuelas emblemáticas (selectivas académicamente).

Ellos, hacíamos controles y tenían puros siete y cosas así po, y yo decía 'pero cómo sabís esto tan rápido y a mí me cuesta tanto entenderlo', y yo en el colegio me iba súper bien en matemáticas (Mujer, Ingeniería Comercial).

En el relato de esta joven se evidencia un problema de fondo en el funcionamiento del sistema educativo del país y que, según nuestra hipótesis, más que al nivel socioeconómico de la familia o a las capacidades individuales, refiere a la incapacidad del sistema escolar de homogeneizar la formación de sus estudiantes. Así, el reclamo de la estudiante devela la inequidad del sistema en tanto la cobertura de contenidos a la que pueden acceder los jóvenes en los distintos establecimientos educativos.

En diversas ocasiones los estudiantes sienten que no avanzan al mismo ritmo de sus compañeros y se frustran en la medida de que no consiguen los mismos resultados que en la etapa escolar.

Tenemos compañeros que ya saben todas las materias, al menos en matemáticas, y nosotros como que al menos yo siento que me quedo atrás por no entender una parte, y esa parte me entorpece todo el proceso que tengo que hacer para más adelante (Mujer, Bachillerato en ciencias y humanidades).

Pese a la raíz estructural del problema, originada en la desigualdad que organiza el sistema de educación escolar, debe ser encarado y resuelto de manera individual por los estudiantes que ingresan a la universidad. Así, el tratamiento de la frustración y la 
desmotivación que, muchas veces surgen por la dificultad de seguir el ritmo académico, son de exclusiva responsabilidad de los estudiantes.

Este hecho se agudiza para quienes provienen de establecimientos TP, debido a que ese currículo escolar destina una menor cantidad de horas a asignaturas que tienen una gran importancia en la universidad (como matemáticas, química, biología y física). Como los estudiantes tuvieron estas asignaturas solo hasta primero o segundo medio y luego comenzaron a ser preparados para sus carreras TP elegidas, una vez en la universidad experimentan significativos vacíos de contenido.

En el colegio también como era técnico-profesional solamente me pasaron hasta segundo la materia científica y lo que más me costó [en la universidad] es como química y biología porque en el colegio no teníamos muy buenos profes y siempre venían o faltaban (Hombre, Química y Farmacia).

Una vez más observamos en los testimonios las consecuencias individuales del orden institucional, pues cada formación -a través de sus planes de estudio y los perfiles de egreso- define una trayectoria más proclive a la universidad en el caso HC y más inclinado al mercado laboral o a una inserción precaria a la educación superior en el caso TC (Centro de políticas comparadas de Educación, 2016). La política educativa, en su diseño, genera un "quiebre curricular" en donde no solo brinda menores oportunidades de acceso a la educación superior de calidad, sino también mayores barreras para permanecer.

Así, un estudiante TP, que habiendo ingresado vía PSU a ingeniería civil con un 6,8 de promedio y un puntaje ponderado de 694, reconoce que "yo sé que soy capaz, pero por las malas bases que tengo, tengo que esforzarme mucho más que mis compañeros". Estabilizar el rendimiento académico para los estudiantes de formación TC es, en consecuencia, una tarea mucho más ardua, pues la educación que recibieron durante la educación secundaria en la mayoría de los casos carece de afinidad con los contenidos de la carrera universitaria.

\subsection{UNA NUEVA MANERA DE GESTIONAR EL TIEMPO Y EL ESTUDIO EN LA UNIVERSIDAD}

El ingreso a la universidad es vivido por los estudiantes como una experiencia que obliga ajustarse a un régimen temporal de trabajo diferente. La universidad implica una desregulación del marco temporal (Boyer et al., 2001): las exigencias académicas demandan una mayor dedicación de tiempo a los estudiantes, las clases rara vez ocupan la jornada, los horarios son más variables e intermitentes, se experimenta mayor tiempo "libre" y, además, existe mayor discrecionalidad con respecto a la asistencia. Todo ello trae como consecuencia, a su vez, la restructuración de las otras dimensiones y actividades de sus vidas. Aunque las asignaturas son menos que en la escuela, la exigencia y la complejidad de las materias aumenta al punto que llega a ser difícil sobrellevar de manera simultánea a lo largo del semestre todas las asignaturas inscritas.

Por ello, la adquisición del oficio de estudiante se juega en el tiempo (Coulon, 2005). Tras los testimonios, emerge una imagen del tiempo en tanto continente que permite acomodar y redistribuir las tareas; un continente, eso sí, rebasado por el contenido del trabajo universitario. Desde el ángulo de la temporalidad, así, el ingreso a la universidad es un proceso que con mayor o menor dificultad los estudiantes suelen resolverlo, pero que conlleva un periodo de ajuste, de ensayo y error, en el cual se van probando 
distintas estrategias en el uso del tiempo de acuerdo a los resultados obtenidos en las evaluaciones.

Con frecuencia los estudiantes describen esta intensificación del ritmo de estudio como un agobiante encadenamiento de actividades -clases, talleres, controles, pruebas, entre otros- que avanza rápidamente y que exige de una capacidad organizativa que hasta ahora no habían desarrollado. Aquello genera la percepción en los estudiantes de que el calendario de actividades de la universidad avanza con mucha mayor celeridad al del colegio. De esta forma, las exigencias académicas de la universidad al ser mayores intensifican el ritmo de estudio haciendo que los estudiantes lo vivan de manera más rápida. Así, por el desafío que implica ajustarse a la demanda de tiempo del estudio en la universidad, algunos estudiantes creen que, contrariamente a los consejos que suelen recibir, más que la ineficacia o total ausencia de hábitos de estudio, el asunto radica concretamente en cómo saber organizar bien el tiempo.

Hablaban mucho del hábito de estudio, pero yo encuentro que es más saber organizar el tiempo, porque yo entro todos los días a las ocho y yo tengo harto tiempo para estudiar, pero el tema es cómo organizarlo para poder estudiar con todo, más el hábito de estudio es aprender a organizarte (Mujer, Tecnólogo en alimentos).

Esta organización, como se observa, no es algo que ocurra de manera natural en el tránsito del colegio a la universidad. En esta nueva etapa los estudiantes no solo deben aprender los contenidos que se les enseña en las asignaturas de sus carreras, sino que también deben aprender por sí mismos cómo organizar su tiempo para aprender. A eso es precisamente a lo que apuntó Lahire (1997) al señalar que la socialización ocurre en la organización del tiempo y en la articulación del tiempo de estudio y el tiempo libre. En efecto, la gestión del tiempo es un elemento central para obtener los resultados académicos esperados, y a la vez, es producto. Es decir, constituye un trabajo por el cual cada estudiante debe armarse sus tiempos para el estudio.

Yo creo el impacto de también armarse los tiempos para poder estudiar porque todos sabemos que uno viene con un nivel bajo, pero organizarse en los estudios, cómo voy a dejar de carretear por estudiar (Mujer, Bachillerato en ciencias y humanidades).

Ahora bien, de manera más precisa, ¿qué significa "armarse" los tiempos de estudio? A partir de los testimonios de los estudiantes emergen tres dificultades asociadas a esta tarea.

\subsubsection{Anticipación del estudio o cuando ya no sirve "calentar" la materia}

Una de las cosas que los estudiantes comprueban tempranamente en las evaluaciones, es lo poco probable de conseguir buenos resultados si es que el estudio no se realiza considerando tiempo de antelación. La organización del tiempo de estudio, en ese sentido, requiere de una anticipación que en el colegio no se solía considerar. Muy por el contrario, si es que algo caracterizó la forma de estudiar de los jóvenes en el colegio, fue que se hacía solo algunos días antes de las evaluaciones.

De esta manera, los estudiantes en la universidad deben romper con lo que hasta entonces les era habitual: que el estudio es una actividad -casi excepcional- que se realiza 
poco tiempo antes de una evaluación. Como aquello se torna inviable en la universidad debido a, por un lado, la cantidad y complejidad de los contenidos de las asignaturas y, por otro, la simultaneidad de evaluaciones de los distintos cursos del semestre; si es que los estudiantes quieren obtener buenos resultados académicos, deben anticipar sus estudios.

Uno siempre tiene que estudiar con anticipación porque el peor estudio es el de tres días antes de la prueba. [...] en mi caso yo estudio dos semanas antes de la prueba, pero no mucho, como dos o tres ejercicios y ya, todos los días, y eso me ha dado hartos resultados (Hombre, Ingeniería Civil Mecánica).

Los estudiantes, toman consciencia de que el estudio debe planificarse a partir de los malos resultados obtenidos en las primeras pruebas. Aquello supone transitar de una lógica de estudio a corto plazo y situada en la inmediatez del presente, a otra orientada hacia los eventos del futuro. En otras palabras, la organización del estudio debe ampliar el rango temporal que los estudiantes solían manejar durante el colegio. La anticipación, en consecuencia, es descubierta como un elemento central del estudio en la universidad.

\subsection{2. ¿Cómo darle prioridad a todo?}

Otra de las dificultades que enfrentan los estudiantes en la organización del tiempo de estudio en la universidad es la exigencia de atender simultáneamente a las distintas asignaturas del semestre. Aquello si bien podría parecer trivial dado que en el colegio los estudiantes tienen que responder a una mayor cantidad de asignaturas; la cantidad y complejidad de los contenidos, sumado a la intensidad del calendario de evaluaciones de diferente tipo, tienen por resultado que tanto la organización de la rutina de estudio como la mantención de un buen desempeño académicos constituyen un desafío mayor.

Yo soy de clases en la mañana, de las ocho de la mañana y acá me quedo como hasta las nueve, y a mi casa llego como a las once de la noche, y es como, trato de organizarme, de darle prioridad a todo, como, de todo un poco, pero aun así me cuesta (Mujer, Ingeniería en ejecución en Minas).

En lo anterior cabe considerar, por supuesto, la capacidad de priorizar que deben desarrollar los estudiantes, de decidir qué es lo que más importante y, por tanto, a qué se le dedicará más tiempo. Efectivamente, pues de la carga a académica del semestre, no todas las asignaturas tienen igual importancia, ni tampoco el mismo grado complejidad en cuanto a los contenidos. Por esta razón, en vistas de un buen rendimiento académico, los estudiantes deben aprender a distribuir de manera adecuada el tiempo de estudio que le dedican a cada asignatura.

El ejercicio de dosificar el tiempo de estudio de manera diferenciada según sea la asignatura puede considerarse, un aprendizaje de orden práctico y, en la medida en que se orienta a maximizar las posibilidades de obtener buenos resultados, estratégico. Sin embargo, el despliegue de estrategias puede observarse no solamente en función de los buenos resultados, sino también cuando se hace necesario salvar una situación. Lo anterior sucede cuando, por ejemplo, existen pocas probabilidades de aprobar una asignatura (considerando las malas calificaciones previas) y se prioriza destinar el tiempo de estudio a otras materias. 
Yo creo que esta semana ha sido o va a ser la más pesada, porque tenemos tres pruebas, dos trabajos que entregar, y por ser ahora no estudié nada de cálculo, entonces ahí ya me sobrecargué y le di la preferencia estudiar física. [...] o sea yo prefiero estudiar física porque sé que cálculo ya es un mínimo porcentaje de poder pasarlo y física está ahí po', pero hay opciones" (Hombre, Ingeniería en Ejecución Mecánica).

La elección de abandonar una asignatura también se relaciona con el desarrollo de procesos de aprendizaje que no son propiamente contenidos disciplinares o académicos, sino que más bien se relacionan con el entendimiento de las "reglas del juego" que rigen la universidad. En efecto, conforme pasa el semestre y los estudiantes van conociendo el modo en que funciona la universidad, despliegan estrategias a través de las cuales buscan obtener el máximo de provecho (o bien, disminuir al mínimo las posibilidades de fracasar) utilizando las reglas del juego a su favor.

\subsubsection{Conciliar el estudio con el tiempo libre}

La última dificultad en cuanto al tiempo que mencionaron los estudiantes estuvo relacionada con compatibilizar el tiempo que les exige la universidad con los otros espacios de su vida. Como la demanda temporal del estudio universitario absorbe tiempo que otrora los estudiantes utilizaban para otras cosas, el ingreso a la universidad, en ese sentido, conlleva un reajuste significativo de sus rutinas y de las temporalidades de los distintos espacios de sus vidas. Nuevamente los estudiantes se ven enfrentados a priorizar, ya no en cuanto a la distribución de tiempo de estudio en las distintas asignaturas, sino respecto al tiempo de estudio en relación a las otras actividades de sus vidas personales. De esta manera, si es que en el colegio el tiempo del estudio siempre se encontró en tensión con el tiempo libre, en la universidad la primacía del primero sobre el segundo adquiere para estos estudiantes una legitimidad casi incuestionable.

Los estudiantes ajustan sus rutinas para responder a las demandas universitarias. En la mayoría de los casos, esto implica la reducción de horas de sueño, medida que parece necesaria especialmente al inicio del semestre, cuando todavía lo estudiantes no saben bien cómo enfrentar la nueva carga de estudio. En tal situación, como se aprecia a continuación, dormir menos aparece como una solución extrema y provisoria mientras no se logre dominar los contenidos de las asignaturas y se estructure una forma de estudiar.

A mí me pasó al inicio que casi ni dormía, por el tema de nivelarme, me costó mucho acostumbrarme al ritmo y ahora ya que sé al menos cómo empezar a resolver las cosas, solamente hago ejercicios, tengo mis horarios y listo. [...] por ejemplo llego a la casa, dos horas para leer todo lo que pasa en el día, después jugar un rato, después preparar lo que viene más cerca (Hombre, Ingeniería Civil Eléctrica).

De este modo, a medida que avanza el semestre, los estudiantes prueban diferentes formas de ajuste entre el tiempo de estudio y el que destinan a otras actividades, así, paulatinamente van encontrando las soluciones que mejor se adecúan a sus circunstancias personales. 


\section{DISCUSIÓN Y CONCLUSIONES}

Esta investigación representa un intento por comprender las experiencias de un grupo de estudiantes de primer año de la Universidad de Santiago, a través de una lectura atenta de sus vivencias, interacciones e intercambios con el nuevo entorno universitario. El sentido que la animó fue de poder entender no solo las experiencias de los estudiantes, sino a la universidad misma a través de lo que ellos relatan. Así, en términos de Felouzis (2001), realizamos la tentativa de comprender la experiencia de los estudiantes y la universidad que los recibe, tomando distancia, por un lado, de enfoques que consideran a los estudiantes fuera de todo contexto concreto y de la universidad como una entidad abstracto e inaccesible y, por otro lado, de las perspectivas que mediante la generación indicadores de desempeño buscan orientar las decisiones a tomar en materia de gestión universitaria.

A su vez, cabe destacar un tercer distanciamiento relacionado con el abordaje mainstream de las investigaciones sobre las experiencias de los estudiantes durante el primer año universitario. En Chile, las investigaciones que analizan la transición a la educación superior dan cuenta de las numerosas dificultades que los estudiantes deben enfrentar para permanecer en el sistema educativo. Con frecuencia, estas dificultades son analizadas desde la perspectiva de la reproducción social y sus dispositivos analíticos asociados, reconociendo en las experiencias individuales una primacía de las lógicas institucionales que explicaría la disparidad de la preparación académica: una consecuencia del ingreso de segmentos sociales cuyo capital cultural, heredado e incorporado en un habitus específico, no se ajusta al que tradicionalmente ingresaba a la universidad.

Bajo esta perspectiva, los estudios han reconocido que las principales dificultades que deben enfrentar los jóvenes durante su transición se encuentran asociadas a la falta de hábitos de estudio y escaso manejo de contenidos; la percepción de desigualdad respecto de la cobertura de contenidos trabajados durante la secundaria; la adquisición de reglas y códigos culturales distantes al capital cultural heredado; el poco tiempo disponible para participar en actividades de extensión propias de la vida universitaria y falta de redes de apoyo apropiadas para resolver dudas o conflictos vocacionales (González et al., 2005; Canales y De los Ríos, 2009; Leyton et al., 2012; Gallardo et al., 2014, Soto-Hernández, 2016).

Si bien nuestra investigación coincide y reafirma la pregnancia de estos hallazgos, busca eludir la atribución del origen de estos obstáculos vividos por los estudiantes a la formula generatriz de un habitus. Ello porque en la sociedad de nuestros días es difícil sostener sin más la correspondencia del actor vis a vis su posición social, que permitió otrora la comprensión e, incluso, predicción del actuar de los individuos (Martuccelli, 2007). Aquello, por supuesto, no significa negar el peso de las estructuras, instituciones o posiciones sociales en la conformación de las experiencias individuales. Significa, más bien, asumir que las posiciones sociales se diversifican, los procesos de socialización son múltiples y, en consecuencia, las experiencias individuales cada vez más singulares.

Finalmente, a partir de las limitaciones de la presente investigación, consideramos que la investigación de las ciencias sociales y de la educación en torno a la universidad y la experiencia de sus estudiantes, podría avanzar de manera fecunda al considerar las siguientes dimensiones. En primer lugar, profundizar en las experiencias de los estudiantes a través de enfoques como el biográfico o del curso de vida ${ }^{2}$ y de estudios cualitativos de

Lo que en el mundo anglosajón se denomina como lifecours y en el francófono como parcours de vie. 
carácter longitudinal. La experiencia del ingreso, aunque significativa, parece ser solamente la introducción a una historia que tendrá un desarrollo todavía más largo. Un proyecto de investigación de largo aliento en el cual investigadores tengan contacto con un grupo de estudiantes en el avance y en diferentes puntos de su trayectoria, permitiría conocer qué ocurre con los estudiantes durante los años siguientes, qué obstáculos, puntos de inflexión y/o soportes encuentran en el desarrollo de su estancia en la universidad.

En segundo lugar, y en estrecha relación con lo anterior, considerar las biografías y trayectorias de primer año como una herramienta no solo para entender las experiencias de los estudiantes, sino para comprender el tipo de universidad y de sistema universitario que se ha forjado en el Chile de los últimos lustros. Por último, ahondar en las particularidades de las experiencias universitarias según carreras o programas de estudio, ya que se trata de verdaderas matrices de socialización, altamente diferenciadas según las formas de trabajo universitario y por la especificidad sociocognitiva de las lógicas intelectuales y pedagógicas que estas involucran (Millet, 2003).

\section{REFERENCIAS BIBLIOGRÁFICAS}

Araujo, K. y Martuccelli, D. (2011). La inconsistencia posicional: un nuevo concepto sobre la estratificación social. Revista CEPAL, Abril (103), 165-178. https://repositorio.cepal.org/ handle/11362/11453

Bellei, C., Cabalin, C. y Orellana, V. (2014). The 2011 Chilean student movement against neoliberal educational policies. Studies in Higher Education, 39(3), 426-440. doi: 10.1080/03075079.2014.896179

Bourdieu, P. \& Passeron, J. C. (2012). Les héritiers les étudiants et la culture. Éditions de Minuit.

Boyer, R., Coridian, C. \& Erlich, V. (2001). L'entrée dans la vie étudiante. Socialisation et apprentissages. Revue Française de Pédagogie, 136(1), 97-105. https://doi.org/10.3406/ rfp. 2001.2829

Brunner, J. (2008). El sistema de educación superior en Chile: un enfoque de economía política comparada. Avaliação: Revista da Avaliação da Educação Superior (Campinas), 13(2), 451486. https://dx.doi.org/10.1590/S1414-40772008000200010

Canales, A. y De los Ríos, D. (2009). Retención de estudiantes vulnerables en la educación universitaria chilena. Revista Calidad en la Educación, 30, 49-83.

Canales, M. (2006). Metodologías de investigación social. Lom.

Centro de políticas comparadas de Educación. (2016). Estudio sobre transiciones educativas en la enseñanza media y definiciones de la política para este nivel educativo. http:// biblioteca.digital.gob.cl/bitstream/handle/123456789/311/INFORME\%20FINAL\%20 TRANSICIONES\%2c\%202016.pdf?sequence $=1 \&$ isAllowed $=y$

Chiroleu, A. (2013). ¿Ampliación de las oportunidades en la educación superior o democratización? Cuatro experiencias en américa latina. Revista Electrónica Actualidades Investigativas en Educación, 13(3). Recuperado desde: https://www.redalyc.org/articulo.oa?id=447/44729878024

Coulon, A. (2005). Le métier d'étudiant: l'entrée dans la vie universitaire. Presses Universitaires de France.

Dubet, F. (1994). Dimensions et figures de l'expérience étudiante dans l'université de masse. Revue française de sociologie, 511-532. https://www.persee.fr/doc/rfsoc_0035-2969_1994_ num_35_4_4353

Dubet, F. \& Martuccelli, D. (1997). A l'école: sociologie de l'expérience scolaire. Édition du Seuil. Erlich, V. (1998). Les nouveaux étudiants : un groupe social en mutation. Armand Colin. 
Estudios Pedagógicos XLVII N² 2: 161-178, 2021

EXPERIENCIAS ESTUDIANTILES EN EL PRIMER AÑO UNIVERSITARIO. UNA APROXIMACIÓN DESDE LA

SOCIOLOGÍA DE LA EDUCACIÓN FRANCESA

Espinoza, O. (2017). Privatización de la Educación Superior en Chile: Consecuencias y Lecciones Aprendidas. EccoS Revista Científica, 44, 175-202. https://doi.org/10.5585/eccos.n44.8070

Fave-Bonnet, M. \& Clerc, N. (2001). Des «Héritiers» aux «nouveau étudiants»: 35 ans de recherches. Revue Française de Pédagogie, 136(1), 9-19. https://doi.org/10.3406/rfp.2001.2821

Felouzis, G. (2001). La condition étudiante. Presses Universitaires de France. https://doi.org/10.3917/ puf.felou.2001.01

Gallardo, G., Lorca, A., Morrás, D. y Vergara, M. (2014). Experiencia de transición de la secundaria a la universidad de estudiantes admitidos en una universidad tradicional chilena (CRUCH) vía admisión especial de carácter inclusivo. Pensamiento Educativo, 51(2), 135-151. https://doi. org/10.7764/PEL.51.2.2014.10

González, L. E. (Col.); Uribe, D. \& González, S. (2005). Estudio sobre la repitencia y deserción en la educación superior chilena. UNESCO/IESALC.

Grignon, C. \& Gruel, L. (1999). La vie étudiante. Presses Universitaires de France.

Guzmán, C. (2002). Reflexiones en torno a la condición estudiantil en los noventa: los aportes de la sociología francesa. Perfiles Educativos, XXIV(97-98), 38-56.

Jellab, A. (2011). La socialisation universitaire des étudiants. Recherches Sociologiques et Anthropologiques, 42(2), 115-142. https://doi.org/10.4000/rsa.732

Lahire, B. (1997). Les manières d'étudier. La Documentation Française.

Leyton, D., Vásquez, A. y Fuenzalida, V. (2012). La experiencia de estudiantes de contextos vulnerables en diferentes Intituciones de Educación Superior Universitaria (IESU): Resultados de investigación. Calidad en la educación, 37, 61-97. https://dx.doi.org/10.4067/S071845652012000200003

Martinic, R. (2019). ¿Qué hay tras la permanencia universitaria? Los cambios más significativos en el acompañamiento académico. Educação e Pesquisa, 45. https://doi.org/10.1590/s16784634201945190724

Martuccelli, D. (2007). Cambio de rumbo. La sociedad a escala del individuo. Santiago: Lom.

Micin, S., Farias, N., Carreño, B. y Urzúa, S. (2015). Beca Nivelación Académica: la experiencia de una política pública aplicada en una universidad chilena. Calidad en la Educación, 42, 189-208. https://dx.doi.org/10.4067/S0718-45652015000100007

Millet, M. (2003). Les étudiants et le travail universitaire: Étude sociologique. Presses Universitaires de Lyon.

Martuccelli, D. (2007). Cambio de Rumbo: la Sociedad a Escala del Individuo. Lom.

Onwuegbuzie, A., Dickinson, W., Leech, N. \& Zoran, A. (2009). A Qualitative Framework for Collecting and Analyzing Data in Focus Group Research. International Journal of Qualitative Methods, 8(3), 1-21. https://doi.org/10.1177/160940690900800301

Renaut, A. (1995). Les révolutions de l'université : essai sur la modernisation de la culture. CalmannLévy (Liberté de l'esprit).

Soto-Hernández, V. (2016). Estudiantes de primera generación en Chile: una aproximación cualitativa a la experiencia universitaria. Revista complutense de educación, 27(3); 1157-1173. https://doi. org/10.5209/rev_RCED.2016.v27.n3.47562

Strauss, A. y Corbin, J. (2002). Bases de la investigación cualitativa : técnicas y procedimientos para desarrollar la teoría fundada. Editorial Universidad de Antioquía, Facultad de Enfermería de la Universidad de Antioquía.

Valenzuela, J. P., Bellei, C. y De los Ríos, D. (2014). Socioeconomic school segregation in a marketoriented educational system. The case of Chile. Journal of Education Policy, 29(2), 217-241. https://doi.org/10.1080/02680939.2013.806995 